\title{
Nursing Education in Nepal: Historical Perspective
}

\author{
Ramesh Sigdel \\ Asst. Professor \\ IoM, Maharajgunj Medical Campus \\ Kathmandu
}

History of nursing can be described with the role of Florence Nightingale, who was born in Italy on 12 May 1820. In 1837, whilst in the gardens at Emblem, she had what she described as her "calling" the voice of God calling to do her work but she had no idea what that work was \& then she developed on interest i.e. visiting to the home of the sick in the local villages \& began to investigate hospital and nursing. Nursing was started at her time \& for the whole life. She has been working to improve health standard in the field of nursing taking the care of sick, disabled \& injured people from the home, community to the various being the victim of war. Florence Nightingale is only the one who raised nursing to the level of a respectable profession for women. In Nepal the history of nursing could be described in following time periods;

\section{History before 1972 (2029)}

Traditionally care was provided by women in the family. Some social religious group such as Gubhaju, Dhamighakri, Priest, Dyamaju, Sudeni, Janne Manche, in the care, treatment of such people. Now these people are known as traditional healers. Along with the changes during the various periods in the society, many changes also happened in the health care patterns. Care was extended from the home to the institutions as the Bir Hospital, the eldest hospital of Nepal was established in 1896 AD (1947 BS).

There were no nurses to care patient during the period of 1947-1987 BS. The authorities realized the need of nurses to provide care to the patients and then four Nepalese girls were sent to India for 18 months midwifery course and they were posted in Bir Hospital after completing the course in 1987 BS. In 2002 BS other Nine Ladies were sent in India for midwifery training and posted in Bir Hospital. In 2009 BS Ms. Uma Devi Das and Ms. Rukmini Chardn Shresth were sent in India to study registered Nurses with WHO scholarship. Ms. Uma Devi was returned after three and half year and Ms. Charan was come back six months later and both of them started to work in Nepal. In 2010 BS, eight other women were sent for midwifery diploma training in India and they worked in Prashuti Griha at Thapathali later. The first school of Nursing was established in 2013 (1956 A.D.) in Lalitpur Nepal. Later it was shifted in Chhetrapati and Mahaboudha, currently it is located in Maharajgunj, Kathmandu with the name of Nursing Campus Maharajgunj a mother institute of nursing education of the country.

Trained nurses association of Nepal (TNAN) was established in 2018 BS with the initiation of Ms. Loss and Ms. Maningss, Ms. Lamoo Amatya an Indian nurse working in palace was the $1^{\text {st }}$ president of TNAN. She also worked as a nursing school administrator from 2013-2016 BS. Different school of Nursing \& ANM centers were established as following \& upgraded in different time periods.

1) School of Nursing in surendra Bhawan in 2013 (1956).

2) School of Nursing in Nirbhawan, Sanepa 2016 (1959)

3) ANM Training Center in Bharatpur 2019 (1962), stopped in 1992.

4) ANM Training Center Biratnagar in 2023 (1966), upgraded in PCL Nursing in 2044 BS.

5) PCL Training Center Nepalgunj in 2026 (1969), upgraded in PCL Nursing in 2044 BS.

6) PCL Nursing programme in Pokhara in 2041 (1986), upgraded from CMA programme \& introduced BN programme in 2062 (2005).

7) PCL Nursing programme Birgunj in 2043 (1987) upgraded from CMA programme.

History after 1972 (2029)

In 1972 (2029 BS) all academically run schools were placed under T.U. Institute of Medicine. So, Nursing school at Mahaboudha and all the ANM training centers named as ANM extension campus. In 2030 \& 2035 BS, ANM extension campus in Tansen \& Chhetrapati were opened respectively, but now both have been closed. The change reinforced the entry system i.e. SLC should be passed compulsorily for the admission in Nursing. The programme was changed from annual system to semester to match the other programs of university. But, again it was changed in annual system in 1980. The nursing program was $3 \frac{1}{2} 2$ years duration previously (before 1972) \& it was reduced in 3 years later. In 1973 (2030 BS). Princes Prekshya joined nursing training during the regime of king Birendra which brought great change in nursing.

In 1977 (2033) Bachelor of Nursing in midwifery was introduced, further in community (1980), adult (1983) and pediatric (1984) were gradually introduced. Now, the three tracts (Hospital, Community \& Psychiatric Programs) are running well in nursing campus Maharajgunj. In 1995 post graduate (Master in women Health and Women Development) was introduced. Since 2005 (2062) the institute also started four years B Sc Nursing.

Now, there are many other campuses for PCL as well as 
Bachelor programs of Nursing under K.U., P.U., \& C.T.E.V.T. In 1996 (2053) Basic B.Sc Nursing a four year program was established in BPKIHS Dharan. Now, Nursing Campus \& college affiliated to P.U. \& K.U. are lunching since 2005. Ten percent male students were also enrolled in nursing programs since 1986 \& stopped in 1990. Altogether four batches of male students graduated in PCL Nursing Campuses. Now, most of them have completed master level.

\section{Public Health Nursing in Nepal}

Public Health Nurse integrates community involvement and knowledge of the entire population with the personal clinical understandings of health and illness from the experiences of individuals and families within the population. The roles of Public Health Nurse in Nepal are;

$\varnothing \quad$ To work with the community or specific population groups to develop targeted health promotion and disease prevention activities.

$\varnothing$ To evaluate health care services.

$\varnothing \quad$ To provide health education, care, management and primary care to individuals and families who are members of vulnerable populations and high risk groups.

$\varnothing \quad$ To provide input to interdisciplinary programs that monitor, anticipate and respond to health problems in population groups for all diseases or public health threats including bioterrorism. $\varnothing$ To evaluate health trends and risk factors of population groups to determine priorities.

The nurse is the agent who translates and applies the knowledge of health and social sciences to individuals and population groups through specific interventions, programs and advocacy. He or she articulates and translates health and illness experiences of diverse, often vulnerable, individuals and families to the health planners and policy makers. The public health nurse can apply her knowledge of strategies to choose the intervention (s) that meets the needs of a particular community, family or individual. The nurse working in public health should be a voice for members of the community to solve problems and meet desires.

\section{References}

1. Dixit H. Nepal's quest for health (The health services of Nepal). Educational Publishing House, Kathmandu; 2005.

2. Florence Nightingale (1820-1910). Available from http:/ /www.victorianweb.org/history/crimea/florrie.html. Accessed in 4 September 2011.

3. History of Nursing in Nepal. Available from http:// nursingnepal.blogspot.com/2010/02/history-ofnursing-in-nepal.html. Accessed in 4 September 2011. 